\title{
Palladium-Catalyzed Asymmetric Hydrophosphination of Internal Alkynes: Highly Regio- and Stereoselective Construction of Axially Chiral Phosphines
}

\author{
Danqing Ji, ${ }^{a}$ Jierui Jing, ${ }^{a}$ Yi Wang, ${ }^{a}$ Zisong Qi, ${ }^{a}$ Fen Wang, ${ }^{a}$ Xingwei $\mathrm{Li}^{\mathrm{a}, \mathrm{b} *}$ \\ ${ }^{a}$ School of Chemistry and Chemical Engineering, Shaanxi Normal University, Xi'an 710062, China \\ ${ }^{b}$ Institute of Molecular Science and Engineering, Institute of Frontier and Interdisciplinary Sciences, \\ Shandong University, Qingdao 266237, China
}

\begin{abstract}
Palladium-catalyzed unprecedented atroposelective hydrophosphination of internal alkynes has been realized using diarylphosphines, affording C-N axially chiral trisubstituted olefins (vinylphosphines) in excellent regioselectiviry, $(E)$-selectivity, and enantioselectivity. The axial chirality was established via integration of hydrophosphination and dynamic kinetic transformation of the alkynes, with both symmetrical and nonsymmetrical secondary phosphines being applicable. In the latter case, additional P-central chirality has been constructed in good diastereoselectivity.
\end{abstract}

\section{INTRODUCTION}

Chiral phosphorus compounds play an increasingly important role as chiral ligands and catalysts in asymmetric catalysis. ${ }^{1-9}$ Depending on the chiral elements, chiral phosphines can be defined by C- and P-central chirality, axial chirality, and planar chirality. Numerous catalytic synthetic methods have been developed to access chiral phosphines, and classical methods require stoichiometric chiral agents or generate a stoichiometric amount of compound with the opposite configuration. ${ }^{10-14}$ Simple phosphines can be elaborated into chiral ones at the P- or the peripheral reaction sites. Functionalization of the peripheral site may circumvent the strong coordination of the P center. ${ }^{15-21}$ Nevertheless, the preexistence of peripheral functional groups adds to substrate complexity. In this context, catalytic functionalization of the $\mathrm{P}-\mathrm{H}$ bond in tri- or pentavalent phosphorus compounds is advantageous, ${ }^{22-40}$ but it carries formidable challenges for secondary phosphines due to their strong coordination effect, which may lead to deactivation of the metal catalyst together with reduced enantioselectivity.

The asymmetric addition of $\mathrm{P}-\mathrm{H}$ bonds to unsaturated substrates offers an attractive but rather challenging strategy to deliver chiral phosphines in high step- and atom-economy (Scheme 1a). Since 2010, Duan and Leung have independently studied Pd-catalyzed enantioselective hydrophosphination of enones. ${ }^{41,42}$ Very recently, Duan further elegantly extended the substrate to primary phosphines under nickel catalysis. ${ }^{43}$ In 2019 , Wang applied oxa/azabenzonorbornadienes as activated olefins for hydrophsophination. ${ }^{44}$ Yin recently adopted a novel copper-catalyzed approach to address hydrophsophination of acrylamides. ${ }^{45}$ Harutyunyan and Ge realized important hydrophosphination of acrylonitrile catalyzed by Mn complexes via metal-ligand cooperation. $^{46}$ Chi developed NHC-catalyzed hydrophsophination of $\alpha$-Bromoenals. ${ }^{47}$ Besides, enantioselective addition of $\mathrm{P}(\mathrm{V})$-H to different $\pi$-bonds has been accomplished by Dong ${ }^{48}$ and others. ${ }^{49-54}$ In addition, catalytic $\mathrm{P}(\mathrm{III})-\mathrm{H}$ and $\mathrm{P}(\mathrm{V})-\mathrm{H}$ functionalization with an aryl, benzyl, and quinone electrophile also allowed efficient synthesis of diverse P-chiral products. ${ }^{55-64}$ In these two categories, the reactions are limited to generation of C- or P-chiral centers. Of note, synthesis of the large family of axially chiral ${ }^{65,66}$ phosphines remains largely untouched via P-H functionalization, although axially chiral P-functionalized biaryls have been constructed by $\mathrm{C}-\mathrm{H}$ bond activation. ${ }^{67,68}$ 
(a) Asymmetric Addition of $\mathrm{P}-\mathrm{H}$ to $\mathrm{C}=\mathrm{C}$ and $\mathrm{C}=\mathrm{N}$ : $\mathrm{C}$ - or P-Central Chirality

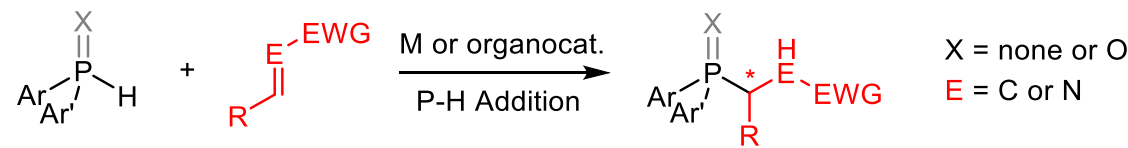

$\mathbf{P}(\mathrm{III})-\mathrm{H}$

Enone, Acrylamide, Cinnamaldehyde, and Acrylonitrile (2010-2021)

(Duan, Leung, Wang, Yin, Chi, Harutyunyan/Ge)

P(V)-H Imine (Tan, 2009), 1,3-Diene (Dong, 2018), Allene (Wang, 2021)

(b) Asymmetric (Di)Functionalization of Internal Alkynes: Axial Chirality<smiles>[R]C#Cc1cccc2ccccc12</smiles><smiles>[R]c1ccc2ccccc2c1-c1c([R])c(C)c2c(c1C)CCC2</smiles>

$[2+2+2] /[4+2]$<smiles>[R]/C=C(/C#N)c1c(O)ccc2ccccc12</smiles>

$\mathrm{Nu}$ addition to 1-alkynylnaphthol<smiles>[R]C1=C(c2c([R])ccc3ccccc23)c2ccccc2CCO1</smiles>

C-H Activation

(c) Asymmetric Hydrophosphination of Internal Alkyne: Axially Chiral Olefin (this work)

Challenges:<smiles>[R]C#Cn1c([R])cc2ccccc21</smiles>

Z/E Selectivity

Enantioselectivity

Scheme 1. Axially Chiral Olefins and Synthesis of Chiral Phosphines via Asymmetric P-H Functionalization

Hydrophosphination of $\mathrm{C} \equiv \mathrm{C}$ bonds generates a vinylphosphine, and terminal alkynes were predominantly used under Pd catalysis. ${ }^{69,70}$ Zhang, ${ }^{71}$ Wang, ${ }^{72}$ and Zhang ${ }^{73}$ independently explored the asymmetric addition of $\mathrm{RArP}(\mathrm{O})-\mathrm{H}$ or RArPH to terminal alkynes for synthesis of P-chiral products. On the other hand, construction of axially chiral arenes has been enabled by annulative coupling of sterically hindered alkynes (Scheme 1b). Thus, the majority of the studies focus on metal-catalyzed [2+2+2] cyclotrimerization of alkynes toward construction of axially chiral biaryls, ${ }^{74,75}$ and Ni-catalyzed extension to related[4+2] annulation has also been developed by Tan and Liu. ${ }^{76}$ Our group recently developed Rh-catalyzed C-H activation of arenes and coupling with sterically hindered alkynes en route to axial chirality by resorting to directing group-metal interactions, and axially chiral open-chain olefins have also been constructed. ${ }^{77-79}$ In contrast, asymmetric hydrofunctionalization of alkynes that affords trisubstituted axially chiral olefins remains underexplored. This is likely ascribed to the intrinsically low reactivity of sterically hindered alkynes and low atropostability of trisubstituted olefins. Nevertheless, Tan elegantly applied alkynals as activated alkynes toward construction of trisubstituted acroleins via formation of an allene intermediate. ${ }^{80,81}$ Yan developed organocatalyzed coupling of 1-alkynyl-2-naphthols with bulky nucleophiles in two- or three-component reactions, with vinylidene ortho-quinone methide as a key intermediate. ${ }^{82,83}$ Despite these nucleophilic additions, the applicability of P-H nucleophiles has not been demonstrated toward construction of axially chiral olefin. 
In addition to the intrinsically low reactivity of sterically hindered alkynes that are required toward construction of axial chirality, hydrophosphination reactions are generally plagued by inhibition of the P(III)$\mathrm{H}$ substrate and the tertiary phosphine product, which render the enantioselective control a formidable challenge and also accounts for the limited asymmetric systems of hydrophosphination when compared to hydrophosphorylation/hydrophosphinylation. The regio- and Z/E selectivity also add to the challenge. ${ }^{69-73}$ Our design plan is to employ sterically hindered internal alkynes via substrate activation. ${ }^{84}$ To address the phosphine inhibition, the chiral ligand must be judiciously selected to both impart chiral induction and to overcome phosphine substrate/product inhibition. We now report palladium-catalyzed enantioselective hydrophosphination of 1-indolylacetylenes using both symmetric and nonsymmetric secondary phosphines (Scheme 1c), affording axially and P-chiral vinylphosphines.

\section{RESULTS AND DISCUSSION}

We initiated our studies with the optimization of the hydrophosphination of alkyne 1a using $\mathrm{Ph}_{2} \mathrm{PH}$ under palladium catalysis (Table 1 and Supplemental Information). A large set of chiral bidentate ligands were screened at $30{ }^{\circ} \mathrm{C}$, and decay of the enantioselectivity with time was observed in most cases as the reaction proceeded. Among them, $(S, S)$-BDPP, QuinoxP, and Josiphos ligands seemed to outperform others and offered good enantioselectivity. Generally higher enantioselectivity was obtained when a more electron-rich $\left(S_{\mathrm{P}}, R\right)$-Josiphos SL-J003-1 (L12) was used (entries 1-14). Screening of the palladium source indicated that $\operatorname{Pd}(\mathrm{acac})_{2}$ was superior to $\mathrm{Pd}(\mathrm{OAc})_{2}$ and others in terms of enantioselectivity (entries 15-17). Evaluation of solvents returned $\mathrm{PhMe}$ or $\mathrm{PhCl}$ as the more suitable one (entries 18-21). Introduction of $\mathrm{CsOAc}$ further improved the enantioselectivity to $94 \%$, and the product was isolated in excellent yield (entry 23). Other acid or base additives tended to give inferior results (entries 22, 24 and 25). The initial hydrophosphination product 3' turned out to be moderately stable under air at ambient temperature, and it was converted to the oxide for convenience of characterization.

Table 1. Optimization of Reaction Conditions ${ }^{\mathrm{a}}$

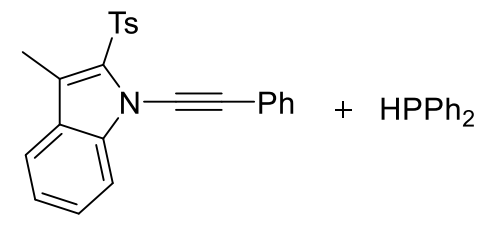

1 a

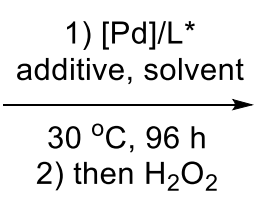

$2 a$

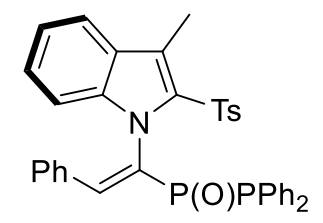

3

\begin{tabular}{lllllll}
\hline Entry & {$[\mathrm{Pd}]$} & $\mathrm{L}^{*}$ & Additive & Solvent & Yield $(\%)$ & Ee $(\%)$ \\
\hline 1 & $\mathrm{Pd}(\mathrm{acac})_{2}$ & $\mathbf{L 1}$ & - & $\mathrm{PhMe}$ & 61 & 81 \\
2 & $\mathrm{Pd}(\mathrm{acac})_{2}$ & $\mathbf{L 2}$ & - & $\mathrm{PhMe}$ & 85 & 91 \\
3 & $\mathrm{Pd}(\mathrm{acac})_{2}$ & $\mathbf{L 3}$ & - & $\mathrm{PhMe}$ & 59 & $<5$ \\
4 & $\mathrm{Pd}(\mathrm{acac})_{2}$ & $\mathbf{L 4}$ & - & $\mathrm{PhMe}$ & 82 & 79 \\
5 & $\mathrm{Pd}(\mathrm{acac})_{2}$ & $\mathbf{L 5}$ & - & $\mathrm{PhMe}$ & 58 & 46 \\
6 & $\mathrm{Pd}(\mathrm{acac})_{2}$ & $\mathbf{L 6}$ & - & $\mathrm{PhMe}$ & 56 & 33 \\
7 & $\mathrm{Pd}(\mathrm{acac})_{2}$ & $\mathbf{L 7}$ & - & $\mathrm{PhMe}$ & 63 & 57 \\
8 & $\mathrm{Pd}(\mathrm{acac})_{2}$ & $\mathbf{L 8}$ & - & $\mathrm{PhMe}$ & 46 & 38 \\
9 & $\mathrm{Pd}(\mathrm{acac})_{2}$ & $\mathbf{L 9}$ & - & $\mathrm{PhMe}$ & 46 & 62
\end{tabular}




\begin{tabular}{lllllll}
10 & $\mathrm{Pd}(\mathrm{acac})_{2}$ & L10 & - & $\mathrm{PhMe}$ & 54 & 18 \\
11 & $\mathrm{Pd}(\mathrm{acac})_{2}$ & L11 & - & $\mathrm{PhMe}$ & 61 & 39 \\
12 & $\mathrm{Pd}(\mathrm{acac})_{2}$ & L12 & - & $\mathrm{PhMe}$ & 88 & 92 \\
13 & $\mathrm{Pd}(\mathrm{acac})_{2}$ & $\mathbf{L 1 3}$ & - & $\mathrm{PhMe}$ & 89 & 85 \\
14 & $\mathrm{Pd}(\mathrm{acac})_{2}$ & L14 & - & $\mathrm{PhMe}$ & 56 & 20 \\
15 & $\mathrm{Pd}\left(\mathrm{NO}_{3}\right)_{2} \cdot \mathrm{H}_{2} \mathrm{O}$ & $\mathbf{L 1 2}$ & - & $\mathrm{PhMe}$ & 80 & 87 \\
16 & $\mathrm{Pd}(\mathrm{OH})_{2}$ & $\mathbf{L 1 2}$ & - & $\mathrm{PhMe}$ & 71 & 88 \\
17 & $\mathrm{Pd}(\mathrm{OAc})_{2}$ & L12 & - & $\mathrm{PhMe}$ & 81 & 92 \\
18 & $\mathrm{Pd}(\mathrm{acac})_{2}$ & $\mathbf{L 1 2}$ & - & $\mathrm{THF}$ & 64 & 75 \\
19 & $\mathrm{Pd}(\mathrm{acac})_{2}$ & $\mathbf{L 1 2}$ & - & $\mathrm{EtOAc}$ & 75 & 92 \\
20 & $\mathrm{Pd}(\mathrm{acac})_{2}$ & $\mathbf{L 1 2}$ & - & $\mathrm{PhCl}$ & 63 & 92 \\
21 & $\mathrm{Pd}(\mathrm{acac})_{2}$ & $\mathbf{L 1 2}$ & - & $\mathrm{acetone}$ & 56 & 88 \\
22 & $\mathrm{Pd}(\mathrm{acac})_{2}$ & $\mathbf{L 1 2}$ & $\mathrm{AgOAc}$ & $\mathrm{PhMe}$ & 89 & 88 \\
23 & $\mathrm{Pd}(\mathrm{acac})_{2}$ & $\mathbf{L 1 2}$ & $\mathrm{CsOAc}$ & $\mathrm{PhMe}$ & 93 & 94 \\
24 & $\mathrm{Pd}(\mathrm{acac})_{2}$ & $\mathbf{L 1 2}$ & $\mathrm{BzOH}$ & $\mathrm{PhMe}$ & 59 & 74 \\
25 & $\mathrm{Pd}(\mathrm{acac})_{2}$ & $\mathbf{L 1 2}$ & $\mathrm{Zn}(\mathrm{OAc})_{2}$ & $\mathrm{PhMe}$ & 77 & 93 \\
\hline
\end{tabular}
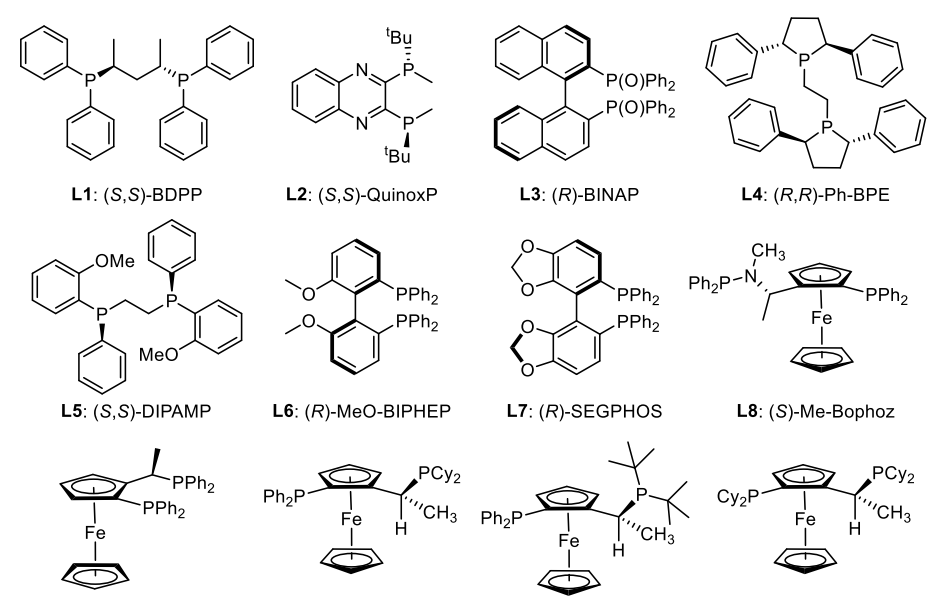

L2: $(S, S)$-QuinoxP

L3: $(R)$-BINAP

L4: $(R, R)-\mathrm{Ph}-\mathrm{BPE}$
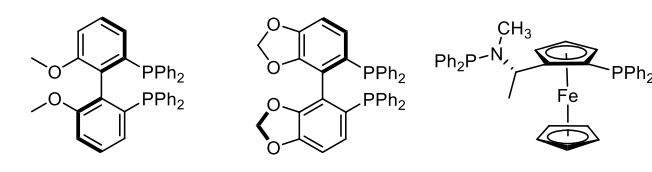

L6: (R)-MeO-BIPHEP

L7: (R)-SEGPHOS

L8: (S)-Me-Bophoz
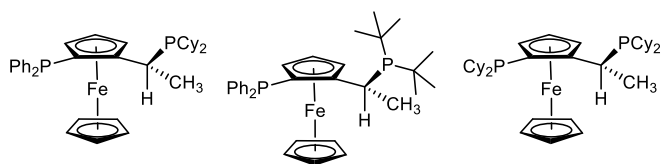

L10: Josiphos SL-J001-1 L11: Josiphos SL-J002-1～L12: Josiphos SL-J003-1

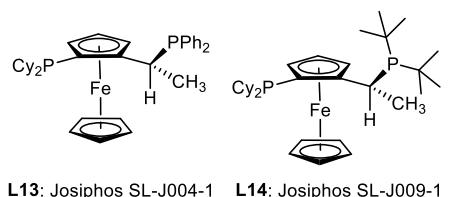

aReaction conditions: 1a $(0.1 \mathrm{mmol}), \mathbf{2 a}(0.2 \mathrm{mmol})$, Pd catalyst $(6 \mathrm{~mol} \%), \mathrm{L}^{*}(9 \mathrm{~mol} \%)$, and additive $(0.3$ equiv) in toluene ( $2 \mathrm{~mL}), 30{ }^{\circ} \mathrm{C}, 96 \mathrm{~h}$; then $\mathrm{H}_{2} \mathrm{O}_{2}$ at $0{ }^{\circ} \mathrm{C}$ for $20 \mathrm{~min}$. Isolated yield. The ee was determined by HPLC analysis using a chiral stationary phase.

Having established of the optimal reaction conditions, we next explored the scope and generality of this coupling system. Under the standard conditions, a broad scope of 1-indolylalkynes has been defined. The 3unsubstituted indolyl substrate also reacted efficiently with slightly reduced enantioselectivity (4, 90\% ee). Variation of the 3-substituent to benzyl or ethyl group was also successful $(\mathbf{5}, \mathbf{6})$. Various substituents such as alkyl, halogen, and methoxy at the 3-, 4-, and 5- positions of the indole ring were compatible (7-13, 88-94\% ee). The absolute configuration of the product $\mathbf{1 2}$ was determined to be (S) by X-ray crystallographic analysis (CCDC 2126532). Extension of the aryl terminus to phenyl groups bearing various electron-donating, - 
withdrawing and halogen substituents at the meta and para positions and to a 2-naphthyl group proved successful (14-20, 86-93\% ee). A 2-fluorophenyl group was also compatible, affording the expected product $\mathbf{2 1}$ in $85 \%$ ee. The presence of a 2-thienyl group gave the product $\mathbf{2 2}$ in high yield albeit with lower enantioselectivity ( $81 \%$ ee). Significantly, extension of the substituent to alkyl (23 and $\mathbf{2 5}$ ) and cyclopropyl group (24) met with no difficulty, and the products were all isolated in excellent enantioselectivities, suggesting the tolerance of the electronic effect of the alkyne. As expected, the coupling of a cyclohexenylsubstituted alkyne with $\mathrm{PHPh}_{2}$ afforded product 26 in high enantioselectivity. The 2-sulfonyl group in the indole functioned as an activating group as well as a bulky group to ensure axial chirality of the product. Extension of the Ts group to other arenesulfonyls was successful (27-29, 88-93\% ee). Furthermore, the sulfonyl group could be replaced by a phenyl group, and under modified conditions using $(R, R)-\mathrm{Ph}-\mathrm{BPE}$ as the chiral ligand, the corresponding product $\mathbf{3 0}$ was isolated in good yield and in $82 \%$ ee. The atropostability of product 3 has been examined, from which $\Delta \mathrm{G} \neq \mathrm{rac}=33.4 \mathrm{kcal} / \mathrm{mol}$ was estimated $\left(100^{\circ} \mathrm{C}\right)$.

\section{Scheme 2. Scope of 1-Indolylacetylenes in Enantioselective Hydrophosphination ${ }^{\text {a }}$}



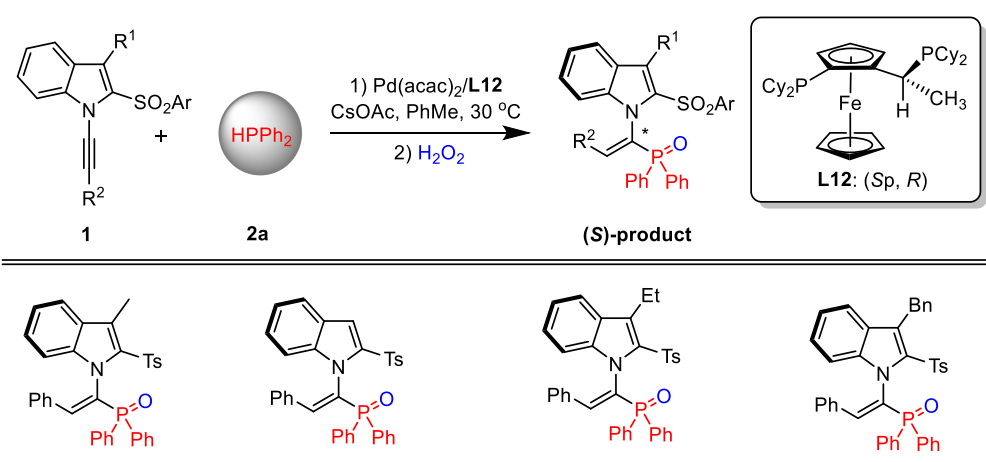

3, $93 \%$ y, $94 \%$ ee

$4,73 \%$ y, $90 \%$ ee

5, $91 \%$ y, $94 \%$ ee

6, $92 \%$ y, $96 \%$ ee
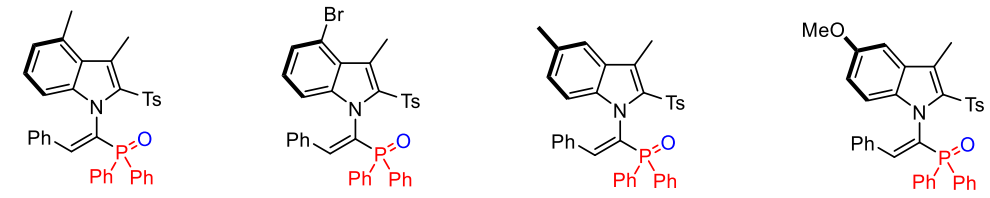

$7,64 \%$ y, $92 \%$ ee

$8,59 \%$ y, $92 \%$ ee

9, $95 \%$ y, $93 \%$ ee
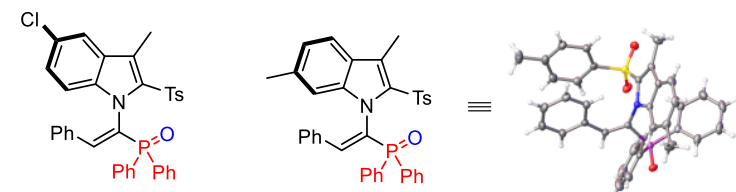

$10,86 \%$ y, $93 \%$ ee

$11,89 \%$ y, $92 \%$ ee

$12,83 \%$ y, $94 \%$ ee

CCDC 2126532

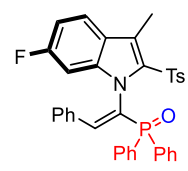

$13,83 \%$ y, $88 \%$ ee
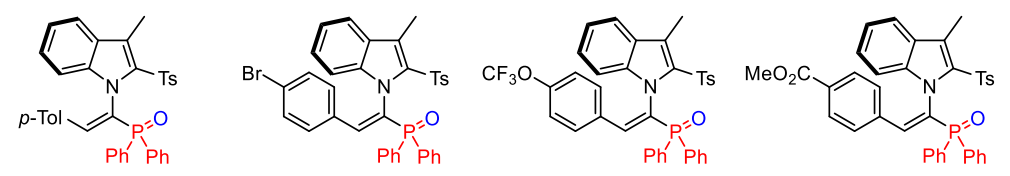

14, $93 \%$ y, $92 \%$ ee

$15,76 \%$ y, $91 \%$ ee

$16,75 \%$ y, $94 \%$ ee

$17,85 \%$ y, $86 \%$ ee
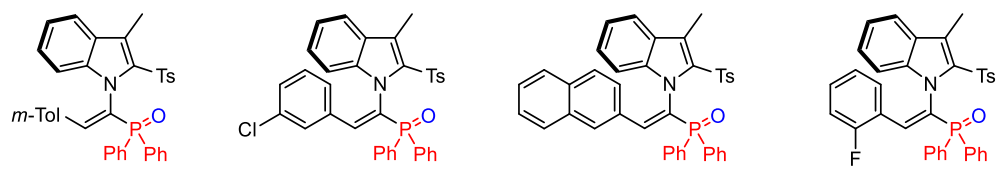

$18,93 \%$ y, $90 \%$ ee

$19,89 \%$ y, $91 \%$ ee

20, $89 \%$ y, $93 \%$ ee

$21,72 \%$ y, $85 \%$ ee
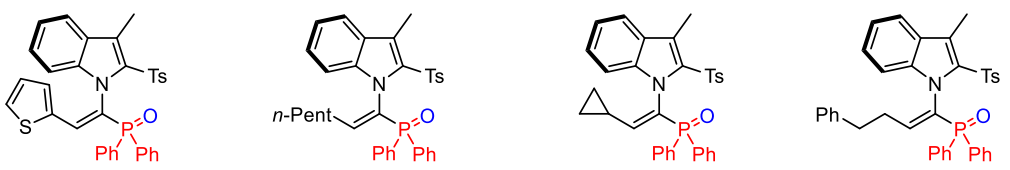

$22,87 \%$ y, $81 \%$ ee

23, $90 \%$ y, $94 \%$ ee

24, $92 \%$ y, $94 \%$ ee
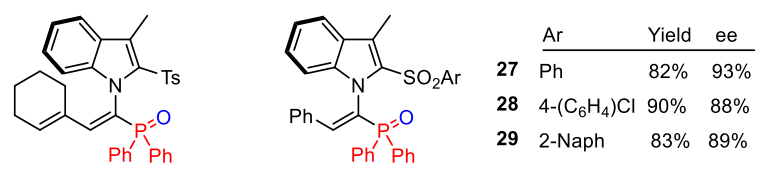

$26,64 \%$ y, $84 \%$ ee

${ }^{a}$ Reaction conditions: 1 (0.1 mmol), 2a (0.2 mmol), Pd(acac) 2 (6 mol\%), CsOAc (30 mol\%), and L12 (9 mol\%) in toluene $(2 \mathrm{~mL}), 30^{\circ} \mathrm{C}, 96 \mathrm{~h}$. Isolated yield. The ee was determined by HPLC analysis.

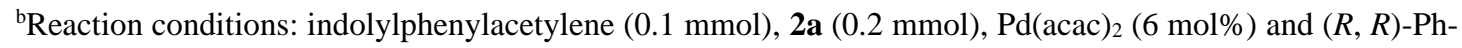
BPE $(9 \mathrm{~mol} \%)$ in toluene $(2 \mathrm{~mL}), 0{ }^{\circ} \mathrm{C}, 96 \mathrm{~h}$.

The scope of the symmetric diarylphosphines was next explored in the coupling with alkyne 1a. Diarylacetylenes bearing diverse electron-donating and -withdrawing groups at the para position all reacted smoothly under the standard conditions (31-39, 91-96\% ee). Phosphines bearing different meta substituted and 
1,3-disubstituted phenyls also reacted in excellent enantioselectivity (40-43, 88-93\% ee). Sluggish reaction was found for ortho substituted diarylphosphines due to the steric effect. Nevertheless, ortho methoxy substituted diphenylphosphine coupled in acceptable yield with high enantioselectivity $(\mathbf{4 4}, 89 \%$ ee).

\section{Scheme 3. Scope of Symmetric Diarylphosphines ${ }^{\mathrm{a}}$}

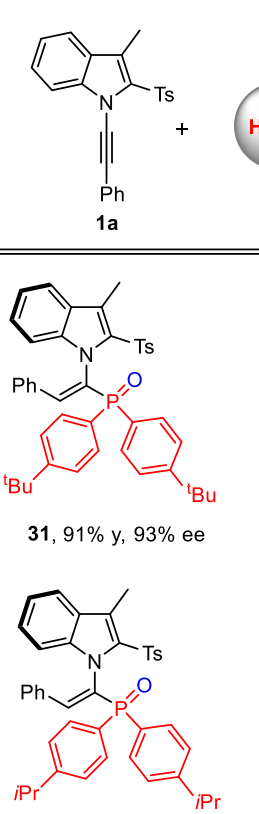

$35,78 \%$ y, $93 \%$ ee
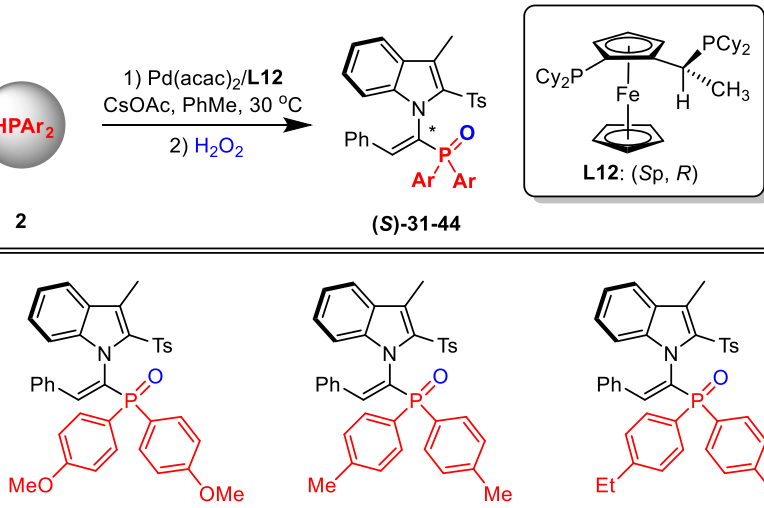

(S)-31-44
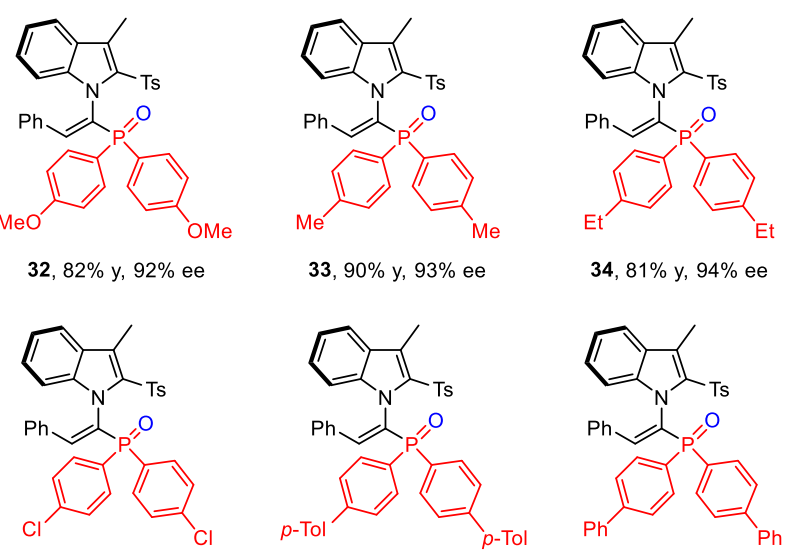

33, $90 \%$ y, $93 \%$ ee

$34,81 \%$ y, $94 \%$ ee

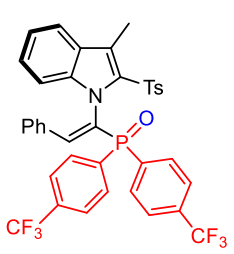

36, $61 \%$ y, $93 \%$ ee
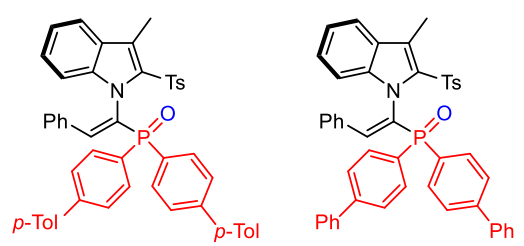

$37,84 \%$ y, $94 \%$ ee

$38,81 \%$ y, $96 \%$ ee
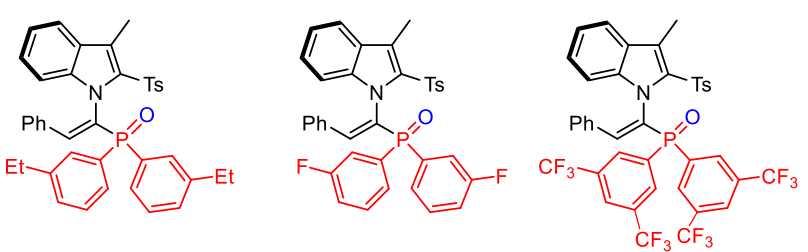

$39,81 \%$ y, $91 \%$ ee

$40,86 \%$ y, $93 \%$ ee

$41,84 \%$ y, $93 \%$ ee

42, $68 \%$ y, $88 \%$ ee
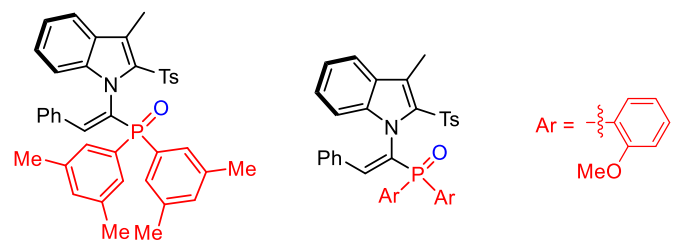

$43,89 \%$ y, $93 \%$ ee

44, $36 \%$ y, $89 \%$ ee

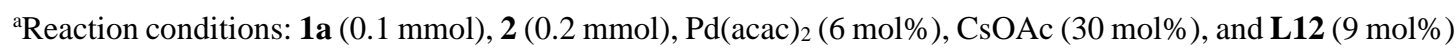
in toluene $(2 \mathrm{~mL}), 30{ }^{\circ} \mathrm{C}, 96 \mathrm{~h}$. Isolated yield.

Having established the scope of symmetrical phosphines, we next moved to coupling using nonsymmetrical secondary phosphines, which will generated both axial and P chirality (Scheme 4). The HPPhMes bearing two sterically biased groups was evaluated and its coupling with alkyne 1a was extensively screened. Our previous catalyst system turned out to be inapplicable. After various studies, a bidentate $(R \mathrm{p}, S)$-Bophoz (L8) was identified as a superior ligand at $0{ }^{\circ} \mathrm{C}$. Thus, the coupling with 1a afforded the hydrophosphination product 45 in good dr (8.5:1) and in excellent enantioselectivity (92\% ee). The scope of the alkyne was also briefly explored. It turned out that indolylalkyne bearing different substituents at the 2- and 4-positions or bearing a different sulfonyl substituent generally underwent smooth coupling in 6.5 to $9.0: 1 \mathrm{dr}$ and in 82-92\% ee for the 
major product (46-52), and similar enantioselectivity was consistently observed for the major and minor diastereomeric products. The major product of $\mathbf{4 7}$ was characterized to be $(S, S)$ configuration by X-ray crystallography (CCDC 2126528) and the rest products were assigned by analogy. A comparable diastereoselectivity was observed when the indole ring is 3 -unsubstituted $(\mathbf{5 3}, 88 \%$ ee $)$. All the above initially hydrophosphinated products are reasonably air-stable, but the diastereomeric products cannot be chromatographically separated unless they were oxidized. Extension of the sterically biased phosphine to phenyl-tert-butylphosphine was also successful, affording the product $\mathbf{5 4}$ in 10:1 dr and 85\% ee.

Scheme 4. Scope of Nonsymmetric Phosphines for Construction of Axial and Central Chirality
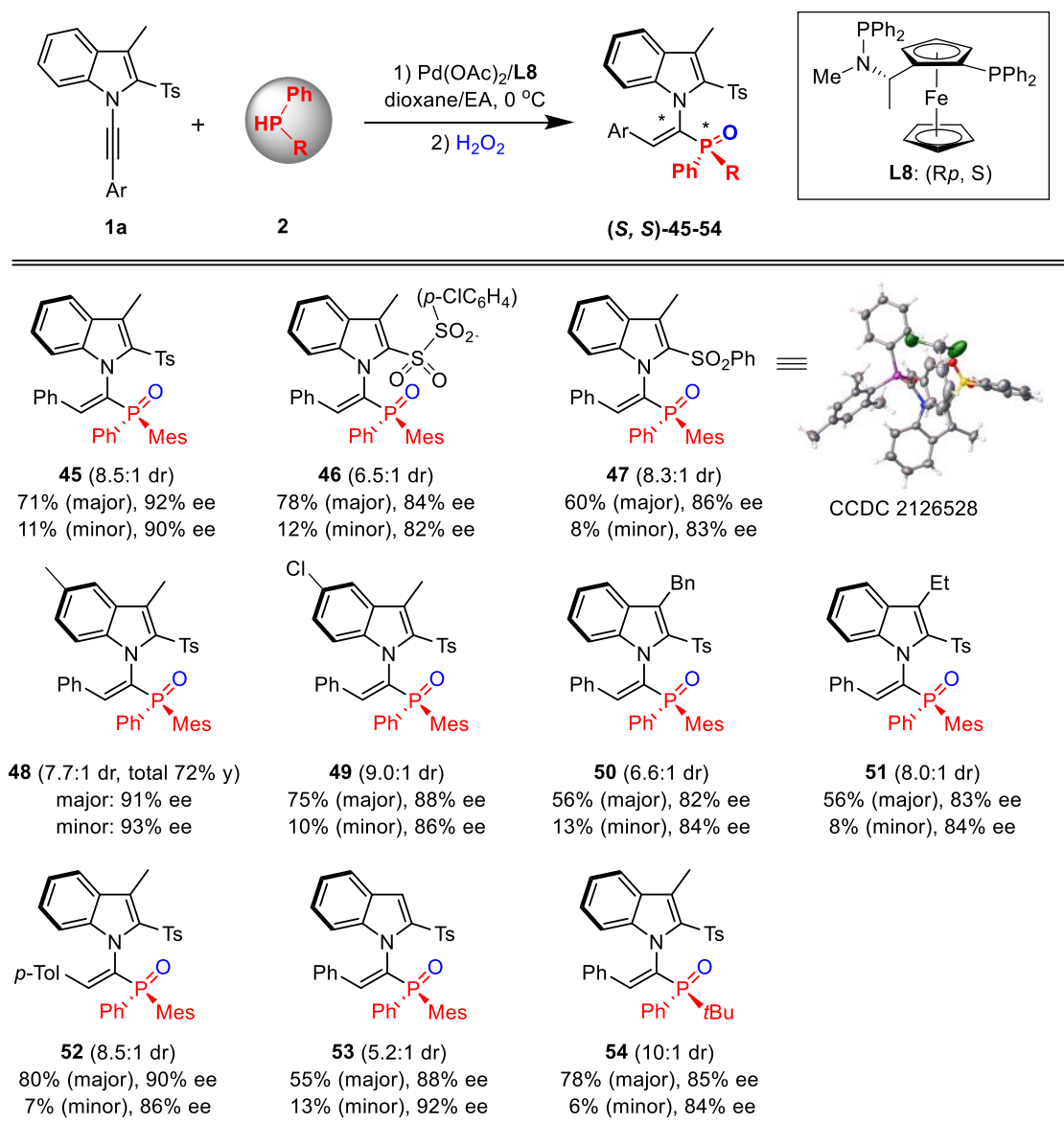

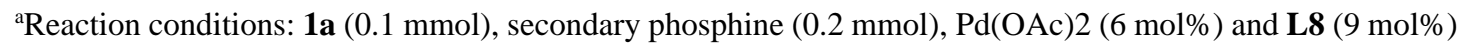
in dioxane $(1 \mathrm{~mL}) /$ EtOAc $(1 \mathrm{~mL})$ at $0{ }^{\circ} \mathrm{C}, 96 \mathrm{~h}$. Isolated yield.

Synthetic applications of representative products have been performed. The coupling of $\mathbf{1 a}$ and $\mathbf{2 a}$ was easily scaled up at a reduced catalyst loading, affording product $\mathbf{3}$ in excellent yield with only slightly lower enantioselectivity (Scheme 5a). In addition to the protection in the oxide form, the initial hydrosphosphination product 3' could also be protected upon treatment with $\mathrm{S}_{8}(\mathbf{5 5})$ or $\mathrm{BH}_{3}-\mathrm{DMS}$ (56, Scheme 5b). Product 3 is somewhat electronically activated, and treatment of $\mathbf{3}$ with $\mathrm{Br}_{2}$ led to electrophilic bromination at the olefinic site, and tetrasubstituted olefin $\mathbf{5 7}$ was obtained in $92 \%$ ee. Palladium-catalyzed transformations of $\mathbf{5 7}$ have been performed, affording the alkynylnation, arylation, and borylation products in high yields (58-60). In all cases, no erosion of enantiopurity was detected.

\section{Scheme 5. Synthetic Applications}


(a)

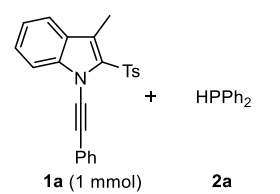

(b)

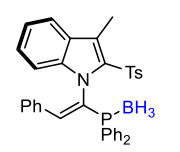

56 91\% (93\% ee)

$\mathrm{BH}_{3} \mathrm{DMS}$
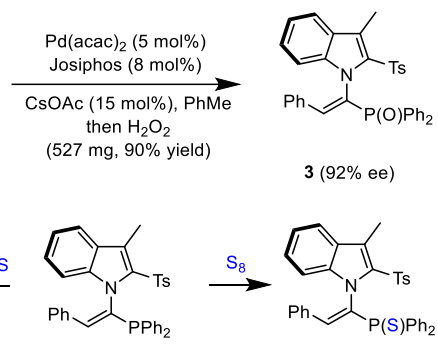

$3^{\prime}(92 \%$ ee $) \quad \mathbf{5 5} 95 \%(92 \%$ ee $)$

(c)

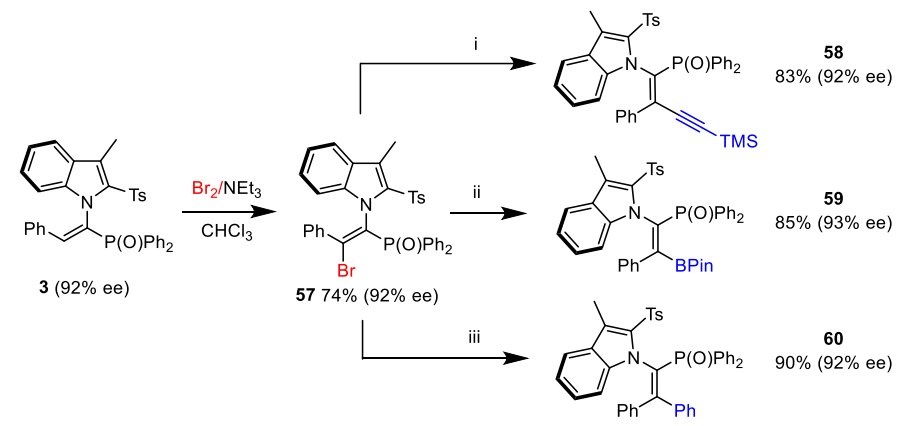

${ }^{\mathrm{a}} \mathrm{TMSC} \equiv \mathrm{CH}, \mathrm{Pd}\left(\mathrm{PPh}_{3}\right)_{2} \mathrm{Cl}_{2}(2 \mathrm{~mol} \%), \mathrm{CuI}, \mathrm{PPh}_{3}, \mathrm{NEt}_{3}, 100{ }^{\circ} \mathrm{C}$.

${ }^{b} \mathrm{~B}_{2} \mathrm{Pin}_{2}, \mathrm{Pd}(\mathrm{dppf}) \mathrm{Cl}_{2}$, AcOK, 1,4-dioxane.

${ }^{\mathrm{c}} \mathrm{PhB}(\mathrm{OH})_{2}, \mathrm{Pd}(\mathrm{OAc})_{2}, \mathrm{PPh}_{3}, \mathrm{~K}_{2} \mathrm{CO}_{3}, \mathrm{THF}, 100{ }^{\circ} \mathrm{C}$.

Preliminary experimental studies have been conducted to explore the reaction mechanism (Scheme 6). As expected, coupling of $1 \mathrm{a}$ with $\mathrm{DPPh}_{2}$ afforded the product 3- $\mathrm{D}_{\mathrm{n}}$ with $\mathrm{H} / \mathrm{D}$ exchange $(\sim 50 \% \mathrm{D})$ at the olefinic position (Scheme 6a), which seems consistent with a pathway that involves protonolysis of a palladium alkenyl. In a competitive experiment, two electronically distinguishable indolylalkynes bearing different groups at the 5-position were allowed to competitively couple with $\mathrm{HPPh}_{2}$. NMR analysis indicated that the 5-methyl substrate completely overrode its 5 -Cl analogue, affording product 9 in excellent yield (Scheme $6 \mathrm{~b}$ ). This may suggest that a more electron-rich indole ring facilitated the coupling with more pronounced substrate activation. To explore possible phosphine inhibition, several control experiments have been conducted. The coupling of 1a with different amounts of $\mathrm{HPPh}_{2}$ all proceeded smoothly with only negligible variations of the enantioselectivity or efficiency (Scheme 6c). In contrast, the employment of an alkyne with a 3-unsusbtituted indole (19') gave decreasingly ee as the amount of $\mathrm{HPPh}_{2}$ increases. In another experiment, the coupling of 1a was conducted in the presence of a chiral phosphine product 10' at the beginning (Scheme 6d), with the efficiency and selectivity essentially unaffected. The different outcomes using these two alkynes may suggest minimal inhibition of $\mathrm{HPPh}_{2}$ and the vinylphosphine product in the cases of substrate 1a, while $\mathrm{HPPh}_{2}$ exerts slight inhibitionin the reaction of $\mathbf{1 a} \mathbf{a}^{\prime}$ as it becomes less electron-rich and somewhat less sterically hindered.

\section{Scheme 6. Mechanistic Studies}


(a)

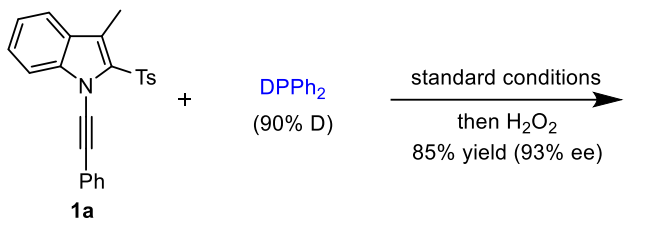

(b)

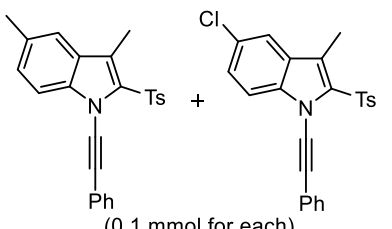

(c)

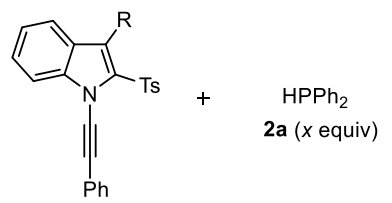

(d)

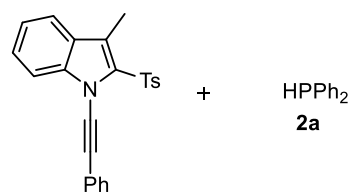

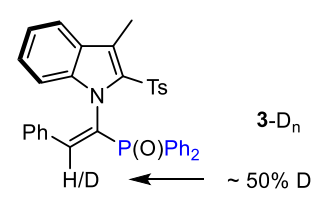

$\mathrm{HPPh}_{2}(0.2 \mathrm{mmol})$ standard conditions

then $\mathrm{H}_{2} \mathrm{O}_{2}$ $85 \%$ yield $(93 \%$ ee)
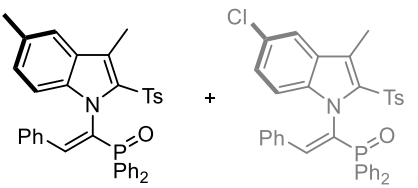

9 (only product)

11 (not detected)
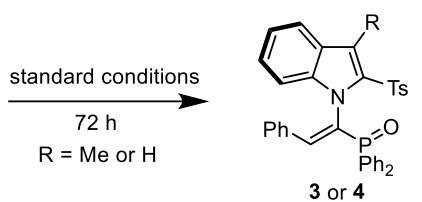

\begin{tabular}{lcc}
\multicolumn{1}{c}{$\boldsymbol{x}$} & $\begin{array}{c}\mathrm{R}=\mathrm{Me} \\
\text { yield/ee } \%\end{array}$ & $\begin{array}{c}\mathrm{R}=\mathbf{H} \\
\text { yield/ee } \%\end{array}$ \\
\hline 1.5 & $74 / 94$ & $66 / 94$ \\
3.0 & $78 / 94$ & $73 / 92$ \\
5.0 & $70 / 93$ & $70 / 89$ \\
10.0 & $68 / 93$ & $48 / 84$
\end{tabular}

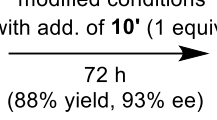

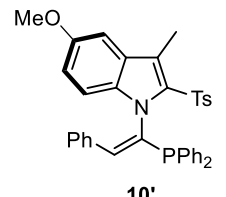

The mechanism of this coupling reaction likely involves the initial deprotonation-ligand substitution between $\mathrm{HPPh}_{2}$ and $\mathrm{L}^{*} \mathrm{PdX} \mathrm{X}_{2}$ to give a $\mathrm{Pd}(\mathrm{II}) \mathrm{PPh}_{2}$ species (Scheme 7). The alkyne coordination is then followed by an enantio-determining migratory insertion of the $\mathrm{PPh}_{2}$ group into the alkyne. This insertion is also regioselective as dictated by both the electronic and steric effects of the 1-indolyl group which functioned toward the same direction. Indeed, the metal tends to end up at the vinyl site that is distal to the bulky aryl group on the basis of our previous studies. ${ }^{77-79}$ Protonolysis of the C-Pd bond eventually furnished the coupled product. In the enantio-determining migratory insertion, the more hindered indole moiety of the alkyne tends to be placed downward and two orientations of the alkyne versus the $\mathrm{PPh}_{2}$ group can be visioned. In the intermediate $\mathbf{A}$, minimal repulsion between the alkyne-attached phenyl group and the alkylphosphino group is experienced. In addition, the $\pi$-acidic alkyne is favorably trans to the more donating alkylphosphino group, which eventually leads to the observed (S) selectivity. The electronic effects of the biased chelating P ligands may play an important role. In fact, the electronic effects of the two P atoms of $\mathbf{L 1 2}$ and $\mathbf{L 8}$ are arranged in the same fashion on the ferrocene backbone, which is in line with the observed (S) axial chirality in both cases. Of note, the hydropalladation pathway, ${ }^{48,69,70}$ that has been suggested in alkyne hydrophosphorylation using $\mathrm{P}(\mathrm{O}) \mathrm{H}(\mathrm{OMe})_{2}$ or $\mathrm{HP}(\mathrm{O}) \mathrm{Ph}_{2}$ seems unlikely because the opposite regioselectivity is expected (Scheme 7, bottom).

Scheme 7. Proposed Reaction Mechanism (Ind = 1-indolyl) 

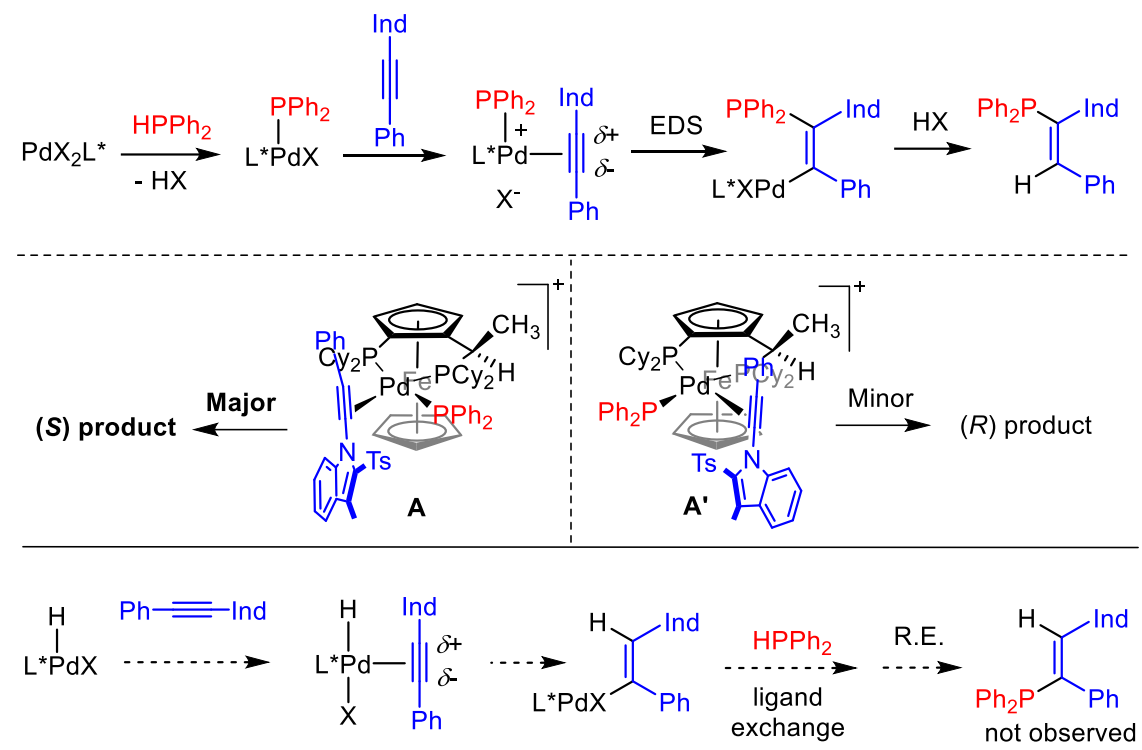

\section{CONCLUSION}

We have realized palladium-catalyzed atroposelective hydrophosphination of sterically hindered internal alkynes using diverse secondary diarylphosphines. The coupling system overcomes the low reactivity of internal alkynes via substrate activation using a sterically bulky but electron-donating 1-indolyl group, affording C-N axially chiral trisubstituted olefins (vinylphosphines) in excellent regioselectivity, $E$-selectivity, and enantioselectivity under mild reaction conditions. The axial chirality was established via integration of hydrophosphination and dynamic kinetic transformation of the alkynes, with both symmetrical and nonsymmetrical secondary phosphines being applicable. In the latter case, additional P-central chirality has been constructed in good diastereoselectivity as well as high enantioselectivity. This hydrophosphination reaction offers a new approach to access underexplored chiral open-chain olefins and may provide new insight into atroposelective functionalization of alkynes.

Further information and requests for resources should be directed to and will be fulfilled by the lead contact Xingwei Li (lixw@snnu.edu.cn).

Materials availability

All materials generated in this study are available from the lead contact without restriction

Data and code availability

The date of the X-ray crystallographic structures of $\mathbf{1 2}$ and $\mathbf{4 7}$ have been deposited in the Cambridge Crystallographic Data Center under accession numbers CCDC: 2126532 and 2126528.

Methods

Full experimental procedures are provided in the supplemental information. 


\section{SUPPLEMENTAL INFORMATION}

Supplemental information can be found online at https://chemrxiv.org

\section{ACKNOWLEDGMENTS}

Financial supports from NSFC (22101167) and SNNU are gratefully acknowledged.

\section{AUTHOR CONTRIBUTIONS}

X.L. conceived the concept and directed the project. D.J., J.J., Y.W., Z.Q., and F.W. conducted the experiments and data analysis. X.L. and Z.Q. wrote the paper with feedback from all other authors.

\section{REFERENCES}

1. Tang, W., Zhang, X. (2003). New Chiral Phosphorus Ligands for Enantioselective Hydrogenation. Chem. Rev. 103, 3029-3069.

2. Xie, J.-H., Zhou, Q.-L. (2008). Chiral Diphosphine and Monodentate Phosphorous Ligands on a Spiro Scaffold for Transition-Metal-Catalyzed Asymmetric Reactions. Acc. Chem. Res. 41, 581-593.

3. Ye, L.-W., Zhou, J., Tang, Y. (2008). Phosphine-triggered Synthesis of Functionalized Cyclic Compounds. Chem. Soc. Rev. 37, 1140-1152.

4. Fernández-Pérez, H., Etayo, P., Panossian, A., Vidal-Ferran, A. (2011). Phosphine-Phosphinite and Phosphine-Phosphite Ligands: Preparation and Applications in Asymmetric Catalysis. Chem. Rev. 111, 2119-2176.

5. Li, W., Zhang, J. (2016). Recent Developments in the Synthesis and Utilization of Chiral $\beta$-Aminophosphine Derivatives as Catalysts or Ligands. Chem. Soc. Rev. 45, 1657-1677.

6. Ni, H., Chan, W.-L., Lu, Y. (2018). Phosphine-Catalyzed Asymmetric Organic Reactions. Chem. Rev. 118, 9344-9411.

7. Guo, H., Fan, Y. C., Sun, Z., Wu, Y., Kwon, O. (2018). Phosphine Organocatalysis. Chem. Rev. 118, 1004910293.

8. Clevenger, A. L., Stolley, R. M., Aderibigbe, J., Louie, J. (2020). Trends in the Usage of Bidentate Phosphines as Ligands in Nickel Catalysis. Chem. Rev. 120, 6124-6196.

9. Xu, G., Senanayake, C. H., Tang, W. (2019). P-Chiral Phosphorous Ligands Based on a 2,3-Dihydrobenzo[d] [1,3] oxaphosphole Mitiffor Asymmetric Catalysis. Acc. Chem. Res. 52, 1101-1112.

10. Pietrusiewicz, K. M., Zablocka, M. (1994). Preparation of Scalemic P-Chiral Phosphines and Their Derivatives. Chem. Rev. 94, 1375-1411.

11. Grabulosa, A., Granell, J., Muller, G. (2007). Preparation of optically pure P-stereogenic trivalent phosphorus compounds. Coord. Chem. Rev. 251, 25-90.

12. Kolodiazhnyi, O. I. (2012). Recent developments in the asymmetric synthesis of P-chiralphosphorus compounds. Tetrahedron: Asymmetry. 23, 1-46.

13. Kortmann, F. A., Chang, M. C., Otten, E., Couzijn, E. P. A., Lutz, M., Minnaard, A. J. (2014). Consecutive dynamic resolutions of phosphine oxides. Chem. Sci. 5, 1322-1327.

14. Glueck, D. S. (2021). Asymmetric Synthesis of P-Stereogenic Secondary Phosphine Oxides (SPOs). Synthesis. 10.1055/a-1582-0169. 
15. Ma, Y.-N., Li, S.-X., Yang, S.-D. (2017). New Approaches for Biaryl-Based Phosphine Ligand Synthesis via $\mathrm{P}=\mathrm{O}$ Directed C $-\mathrm{H}$ Functionalizations. Acc. Chem. Res. 50, 1480-1492.

16. Yin, J., Buchwald, S. L. (2000). A Catalytic Asymmetric Suzuki Coupling for the Synthesis of Axially Chiral Biaryl Compounds. J. Am. Chem. Soc. 122, 12051-12052.

17. Zhou, Y., Zhang, X., Liang, H., Cao, Z., Zhao, X., He, Y., Wang, S., Pang, J., Zhou, Z., Ke, Z., Qiu, L. (2014). Enantioselective Synthesis of Axially Chiral Biaryl Monophosphine Oxides via Direct Asymmetric Suzuki Coupling and DFT Investigations of the Enantioselectivity. ACS Catal. 4, 1390-1397.

18. Feng, J., Li, B., He, Y., Gu, Z. (2016). Enantioselective Synthesis of Atropisomeric Vinyl Arene Compounds by Palladium Catalysis: A Carbene Strategy. Angew. Chem. Int. Ed. 55, 2186-2190.

19. Ji, W., Wu, H.-L., Zhang, J. (2020). Axially Chiral Biaryl Monophosphine Oxides Enabled by Palladium/WJPhos-Catalyzed Asymmetric Suzuki-Miyaura Cross-coupling. ACS Catal. 10, 1548-1554.

20. Zuo, Z., Kim, R. S., Watson, D. A. (2021). Synthesis of Axially Chiral 2,2'-Bisphosphobiarenes via a NickelCatalyzed Asymmetric Ullmann Coupling: General Access to Privileged Chiral Ligands without Optical Resolution. J. Am. Chem. Soc. 143, 1328-1333.

21. Zhang, X., Wang, J., Yang, S.-D. (2021). Enantioselective Cobalt-Catalyzed Reductive Cross-Coupling for the Synthesis of Axially Chiral Phosphine-Olefin Ligands. ACS Catal. 11, 14008-14015.

22. Deprèle, S., Montchamp, J.-L. (2002). Palladium-Catalyzed Hydrophosphinylation of Alkenes and Alkynes. J. Am. Chem. Soc. 124, 9386-9387.

23. Ribière, P., Bravo-Altamirano, K., Antczak, M. I., Hawkins, J. D., Montchanp, J.-L. (2005). NiCl2-Catalyzed Hydrophosphinylation. J. Org. Chem. 70, 4064-4072.

24. Kondoh, A., Yorimistsu, H., Oshima, K., (2007). Copper-Catalyzed anti Hydrophosphination Reaction of 1-Alkynylphosphines with Diphenylphosphine Providing (Z)-1,2-Diphosphino-1-alkenes. J. Am. Chem. Soc. 129, 4099-4104.

25. Bange, C. A., Waterman, R. (2016). Zirconium-Catalyzed Intermolecular Double Hydrophosphination of Alkynes with a Primary Phosphine. ACS Catal. 6, 6413-6416.

26. Novas, B. T., Bange, C. A., Waterman. R., (2019). Photocatalytic Hydrophosphination of Alkenes and Alkynes Using Diphenylphosphine and Triamidoamine-Supported Zirconium. Eur. J. Inorg. Chem. 16401643. 10.1002/ejic.201801079.

27. Baillie, C., Xiao, J. (2003). Catalytic Synthesis of Phosphines and Related Compounds. Curr. Org. Chem. 7, 477-514.

28. Zhao, D., Wang, R. (2012). Recent developments in metal catalyzed asymmetric addition of phosphorus nucleophiles. Chem. Soc. Rev. 41, 2095-2108.

29. Montchamp, J.-L. (2014). Phosphinate Chemistry in the 21st Century: A Viable Alternative to the Use of Phosphorus Trichloride in Organophosphorus. Synthesis. Acc. Chem. Res. 47, 77-87.

30. Wicht, D. K., Kourkine, I. V., Lew, B. M., MuleiNthenge, J., Glueck, D. S. (1997). Platinum-Catalyzed Acrylonitrile Hydrophosphination via Olefin Insertion into a Pt-P Bond. J. Am. Chem. Soc. 119, 5039-5040.

31. Jérôme, F., Monnier, F., Lawicka, H., Dérien, S., Dixneuf, P. H. (2003). Ruthenium catalyzed regioselective hydrophosphination of propargyl alcohols. Chem. Commun. 696-697.

32. Coles, N. T., Mahon, M. F., Webster, R. L. (2018). 1,1-Diphosphines and Sivinylphosphines via Base Catalyzed Hydrophosphination. Chem. Commun. 54, 10443-10446. 
33. Hao, X.-Q., Zhao, Y.-W., Yang, J.-J., Niu, J.-L., Gong, J.-F., Song, M.-P. (2014). Enantioselective Hydrophosphination of Enones with Diphenylphosphine Catalyzed by Bis(imidazoline) NCN Pincer Palladium (II) Complexes. Organometallics. 33, 1801-1811.

34. Hao, X.-Q., Huang, J.-J., Wang, T., Lv, J., Gong, J.-F., Song, M.-P. (2014). PCN Pincer Palladium (II) Complex Catalyzed Enantioselective Hydrophosphination of Enones: Synthesis of Pyridine-Functionalized Chiral Phosphine Oxides as $\mathrm{NCsp}^{3} \mathrm{O}$ Pincer Preligands. J. Org. Chem. 79, 9512-9530.

35. Bange, C. A., Conger, M. A., Novas, B. T., Young, E. R., Liptak, M. D., Waterman, R. (2018). Light-Driven, Zirconium-Catalyzed Hydrophosphination with Primary Phosphines. ACS Catal. 8, 6230-6238.

36. Ghebreab, M. B., Bange, C. A., Waterman, R. (2014). Intermolecular Zirconium-Catalyzed Hydrophosphination of Alkenes and Dienes with Primary Phosphines. J. Am. Chem. Soc. 136, 9240-9243.

37. Dannenberg, S. G., Waterman, R. (2020). A bench-stable copper photocatalyst for the rapid hydrophosphination of activated and unactivated alkenes. Chem. Commun. 56, 14219-14222.

38. Shulyupin, M. O., Kazankova, M. A., Beletskaya, I. P. (2002). Catalytic Hydrophosphination of Styrenes. (2002). Org. Lett. 4, 761-763.

39. Kondoh, A., Yorimitsu, H., Oshima, K. (2007). Copper-Catalyzed anti-Hydrophosphination Reaction of 1Alkynylphosphines with Diphenylphosphine Providing (Z)-1,2-Diphosphino-1-alkenes. J. Am. Chem. Soc. 129, 4099-4104.

40. Ohmiya, H., Yorimitsu, H., Oshima, K. (2005). Cobalt-Catalyzed syn Hydrophosphination of Alkynes. Angew. Chem. Int. Ed. 44, 2368-2370.

41. Feng, J.-J., Chen, X.-F., Shi, M., Duan, W.-L. (2010). Palladium-Catalyzed Asymmetric Addition of Diarylphosphines to Enones toward the Synthesis of Chiral Phosphines. J. Am. Chem. Soc. 132, 5562-5563.

42. Huang, Y., Pullarkat, S. A., Li, Y., Leung, P.-H. (2010). Palladium (II)-Catalyzed Asymmetric Hydrophosphination of Enones: Efficient Access to Chiral Tertiary Phosphines. Chem. Commun. 46, 69506952.

43. Wang, C., Huang, K., Ye, J., Duan, W.-L. (2021). Asymmetric Synthesis of P-Stereogenic Secondary Phosphine Boranes by an Unsymmetric Bisphosphine Pincer-Nickel Complex. J. Am. Chem. Soc. 143, 56855690.

44. Lu, Z., Zhang, H., Yang, Z., Ding, N., Meng, L., Wang, J. (2019). Asymmetric Hydrophosphination of Heterobicyclic Alkenes: Facile Access to Phosphine Ligands for Asymmetric Catalysis. ACS Catal. 9, $1457-$ 1463.

45. Li, Y.-B., Tian, H., Yin, L. (2020). Copper(I)-Catalyzed Asymmetric 1,4-Conjugate Hydrophosphination of $\alpha, \beta$-Unsaturated Amides. J. Am. Chem. Soc. 142, 20098-20106.

46. Pérez, J. M., Postolache, R., Reis, M. C., Sinnema, E. G., Vargová, D., de Viries, F., Otten, E., Ge, L., Harutyunyan, S. R. (2021). Manganese(I)-Catalyzed H-P Bond Activation via Metal-Ligand Cooperation. J. Am. Chem. Soc. 10.1021/jacs.1c10756.

47. Maiti, R., Yan, J.-L., Yang, X., Mondal, B., Xu, J., Chai, H., Jin, Z., Chi, Y. R. (2021). Carbene-Catalyzed Enantioselective Hydrophosphination of $\alpha$-Bromoenals to Prepare Phosphine-Containing Chiral Molecules. Angew. Chem. Int. Ed. 10.1002/anie.202112860.

48. Nie, S.-Z., Davison, R. T., Dong, V. M. (2018). Enantioselective Coupling of Dienes and Phosphine Oxides. J. Am. Chem. Soc. 140, 16450-16454. 
49. Xu, Q., Han, L.-B. (2006). Palladium-Catalyzed Asymmetric Hydrophosphorylation of Norbornenes. Org. Lett. 8, 2099-2101.

50. Ibrahem, I., Rios, R., Vesely, J., Hammar, P., Eriksson, L., Himo, F., Córdova, A. (2007). Enantioselective Organocatalytic Hydrophosphination of $\alpha, \beta$-Unsaturated Aldehydes. Angew. Chem. Int. Ed. 46, 4507-4510.

51. Fu, X., Loh, W.-T., Zhang, Y., Chen, T., Ma, T., Liu, H., Wang, J., Tan, C.-H. (2009). Chiral Guanidinium Salt Catalyzed Enantioselective Phospha-Mannich Reactions. Angew. Chem. Int. Ed. 48, 7387-7390.

52. Khemchyan, L. L., Ivanova, J. V., Zalesskiy, S. S., Ananikov, V. P., Beletskaya, I. P., Starikova, Z. A. (2014). Unprecedented Control of Selectivity in Nickel-Catalyzed Hydrophosphorylation of Alkynes: Efficient Route to Mono- and Bisphosphonates. Adv. Synth. Catal. 356, 771-780.

53. Yang, Z., Wang, J. (2021). Enantioselective Palladium-Catalyzed Hydrophosphinylation of Allenes with Phosphine Oxides: Access to Chiral Allylic Phosphine Oxides. Angew. Chem. Int. Ed. 10.1002/anie.202112285.

54. Wu, Z.-H., Cheng, A.-Q., Yuan, M., Zhao, Y.-X., Yang, H.-L., Wei, L.-H., Wang, H.-Y., Wang, T., Zhang, Z., Duan, W.-L. (2021). Cobalt-Catalysed Asymmetric Addition and Alkylation of Secondary Phosphine Oxides for the Synthesis of P-Stereogenic Compounds. Angew. Chem. Int. Ed. 10.1002/anie.202111137.

55. Huang, Y., Li, Y., Leung, P.-H., Hayashi, T. (2014). Asymmetric Synthesis of P-Stereogenic Diarylphosphinites by Palladium-Catalyzed Enantioselective Addition of Diarylphosphinesto Benzoquinones. J. Am. Chem. Soc. 136, 4865-4868.

56. Beaud, R., Phipps, R. J., Gaunt. M. J. (2016). Enantioselective Cu-Catalyzed Arylation of Secondary Phosphine Oxides with Diaryliodonium Salts toward the Synthesis of P-Chiral Phosphines. J. Am. Chem. Soc. $138,13183-13186$.

57.Zhang, Y., He, H., Wang, Q., Cai, Q. (2016). Asymmetric Synthesis of Chiral P-Stereogenic Triaryl phosphine Oxides via Pd-Catalyzed Kinetic Arylation of Diaryl Phosphine Oxides. Tetrahedron Lett. 57, 5308-5311.

58. Dai, Q., Li, W., Li, Z., Zhang, J. (2019). P-Chiral Phosphines Enabled by Palladium/Xiao-Phos-Catalyzed Asymmetric P-C Cross-Coupling of Secondary Phosphine Oxides and Aryl Bromides. J. Am. Chem. Soc. $141,20556-20564$.

59. Liu, X.-T., Zhang, Y.-Q., Han, X.-Y., Sun, S.-P., Zhang, Q.-W. (2019). Ni-Catalyzed Asymmetric Allylation of Secondary Phosphine Oxides. J. Am. Chem. Soc. 141, 16584-16589.

60. Duan, L., Zhao, K., Wang, Z., Zhang, F.-L., Gu, Z. (2019). Enantioselective Ring-Opening/Oxidative Phosphorylation and P-Transfer Reaction of Cyclic Diaryliodoniums. ACS Catal. 9, 9852-9858.

61. Qiu, H., Dai, Q., He, J., Li, W., Zhang, J. (2020). Access to P-Chiral sec- and tert-Phosphine Oxides Enabled by Le-Phos-Catalyzed Asymmetric Kinetic Resolution. Chem. Sci. 11, 9983-9988.

62. Balázs, L. B., Huang, Y., Khalikuzzaman, J. B., Li, Y., Pullarkat, S. A., Leung, P.-H. (2020). Catalytic Asymmetric Diarylphosphine Addition to $\alpha$-Diazoesters for the Synthesis of P-Stereogenic Phosphinates via P*-N Bond Formation. J. Org. Chem. 85, 14763-14771.

63. Zhang, S., Xiao, J.-Z., Li, Y.-B., Shi, C.-Y., Yin, L. (2021). Copper(I)-Catalyzed Asymmetric Alkylation of Unsymmetrical Secondary Phosphines. J. Am. Chem. Soc. 143, 9912-9921.

64. Dai, Q., Liu, L., Zhang, J. (2021). Palladium/Xiao-Phos-Catalyzed Kinetic Resolution of sec-Phosphine Oxides by P-Benzylation. Angew. Chem. Int. Ed. 10.1002/anie.202111957. 
65. Cheng, J. K., Xiang, S.-H., Li, S., Ye, L., Tan, B. (2021). Recent Advances in Catalytic Asymmetric Construction of Atropisomers. Chem. Rev. 121, 4805-4902.

66. Zheng, J., Gu, Z. (2021). Atropisomerism in Styrene: Synthesis, Stability, and Applications. SynOpen. 5, 6885.

67. Jang, Y.-S., Woźniak, Ł., Pedroni, J., Cramer, N. (2018). Access to P- and Axially Chiral Biaryl Phosphine Oxides by Enantioselective CpxIrIII-Catalyzed C-H Arylations. Angew. Chem. Int. Ed. 57, 12901-12905.

68. Hu, P., Kong, L., Wang, F., Zhu, X., Li, X. (2021). Twofold C-H Activation-Based Enantio- and Diastereoselective $\mathrm{C}-\mathrm{H}$ Arylation Using Diarylacetylenes as Rare Arylating Reagents. Angew. Chem. Int. Ed. 60, 20424-20429.

69. Han, L.-B., Tanaka, M. (1996). Palladium-Catalyzed Hydrophosphorylation of Alkynes via Oxidative Addition of $\mathrm{HP}(\mathrm{O})(\mathrm{OR}) 2$. J. Am. Chem. Soc. 118, 1571-1572.

70. Chen, T., Zhao, C.-Q., Han, L.-B. (2018). Hydrophosphorylation of Alkynes Catalyzed by Palladium : Generality and Mechanism. J. Am. Chem. Soc. 140, 3139-3155.

71. Dai, Q., Liu, L., Qian, Y., Li, W., Zhang, J. (2020). Construction of P-Chiral Alkenylphosphine Oxides through Highly Chemo-, Regio-, and Enantioselective Hydrophosphinylation of Alkynes. Angew. Chem. Int. Ed. 59, 20645-20650.

72. Yang, Z., Gu, X., Han, L.-B., Wang, J. (2020). Palladium-Catalyzed Asymmetric Hydrophosphorylation of Alkynes: Facile Access to P-Stereogenic Phosphinates. Chem. Sci. 11, 7451-7455.

73. Liu, X.-T., Han, X.-Y., Wu, Y., Sun, Y.-Y., Gao, L., Huang, Z., Zhang, Q.-W. (2021). Ni-Catalyzed Asymmetric Hydrophosphination of Unactivated Alkynes. J. Am. Chem. Soc. 143, 11309-11316.

74. Tanaka, K., Nishima, G., Wada, Z., Noguchi, K. (2004). Enantioselective Synthesis of Axially Chiral Phthalides through Cationic [RhI(H8-binap)]-Catalyzed Cross Alkyne Cyclotrimerization. Angew. Chem. Int. Ed. 43, 6510-6512.

75. Tanaka, K. (2009). Transition-Metal-Catalyzed Enantioselective [2+2+2] Cycloadditions for the Synthesis of Axially Chiral Biaryls. Chem. Asian J. 4, $508-518$.

76. Fang, Z.-J., Zheng, S.-C., Guo, Z., Guo, J.-Y., Tan, B., Liu, X.-Y. (2015). Asymmetric Synthesis of Axially Chiral Isoquinolones: Nickel-Catalyzed Denitrogenative Transannulation. Angew. Chem. Int. Ed. 54, 95289532.

77. Wang, F., Qi, Z., Zhao, Y., Zhai, S., Zheng, G., Mi, R., Huang, Z., Zhu, X., He, X., Li, X. (2020). Rhodium (III)-Catalyzed Atroposelective Synthesis of Biaryls by $\mathrm{C}-\mathrm{H}$ Activation and Intermolecular Coupling with Sterically Hindered Alkynes. Angew. Chem. Int. Ed. 59, 13288-13294.

78. Wang, F., Jing, J., Zhao, Y., Zhu, X., Zhang, X.-P., Zhao, L., Hu, P., Deng, W.-Q., Li, X. (2021). RhodiumCatalyzed $\mathrm{C}-\mathrm{H}$ Activation-Based Construction of Axially and Centrally Chiral Indenes through Two Discrete Insertions. Angew. Chem. Int. Ed. 60, 16628-16633.

79. Mi, R., Chen, H., Zhou, X., Li, N., Ji, D., Wang, F., Lan, Y., Li, X. (2021). Rhodium-Catalyzed Atroposelective Access to Axially Chiral Olefins via $\mathrm{C}-\mathrm{H}$ Bond Activation and Directing Group Migration. Angew. Chem. Int. Ed. 10.1002/anie.202111860.

80. Zheng, S. C., Wu, S., Zhou, Q., Chung, L. W., Ye, L., Tan, B. (2017). Organocatalytic Atroposelective Synthesis of Axially Chiral Styrenes. Nat. Commun. 8, 15238. 
81. Wang, Y.-B., Yu, P., Zhou, Z.-P., Zhang, J., Wang, J., Luo, S.-H., Gu, Q.-S., Houk, K. N., Tan, B. (2019). Rational design, enantioselective synthesis and catalytic applications of axially chiral EBINOLs. Nat. Catal. 2, 504-513.

82. Jia, S., Chen, Z., Zhang, N., Tan, Y., Liu, Y., Deng, J., Yan, H. (2018). Organocatalytic Enantioselective Construction of Axially Chiral Sulfone-Containing Styrenes. J. Am. Chem. Soc. 140, 7056-7060.

83. Tan, Y., Jia, S., Hu, F., Liu, Y., Peng, L., Li, D., Yan, H. (2018). Enantioselective Construction of Vicinal Diaxial Styrenes and Multiaxis System via Organocatalysis. J. Am. Chem. Soc. 140, 16893-16898.

84. Kinbara, A., Kasai, H., Sato, K., Watanabe, Y., Yamagishi, T. Nickel-catalyzed regio- and stereoselective hydrophosphinylation of internal ynamides with H-phosphinates. (2018). Tetrahedron. 74, 7068-7073. 